\title{
建筑工程造价管理的现状及完善对策浅析
}

肖寒

成都建工第七建筑工程有限公司

DOI:10.32629/btr.v1i4.1600

[摘 要] 在建筑工程的全过程管理中,造价工程是其中的一个重要的组成部分, 其直接关系着建筑施工单位能否增强核心竞 争力、提高经济效益, 也关系到建筑市场能否健康发展。基于此, 本文探讨了建筑工程造价管理的现状,并对现存问题提出了解 决办法, 以此为大家提供参考。

[关键词] 建筑工程; 造价管理; 完善对策

随着我国社会发展的加速, 城市化进程越来越快, 城市 的基础建设工程越来越多, 规模也越来越大, 这使得建筑行 业也得到飞速发展。在这种情况下, 在进行建筑施工时, 如何 在一定的财力、物力和人力的基础上, 获得尽可能多的效益, 就成为了建筑工程造价管理的新问题。

\section{1 什么是建筑工程造价管理}

建筑工程造价就是指工程项目在建设过程中, 工程建设 的总投入和建设过程中新出现的价值的总称, 也是在完整的 再生产过程中建设项目所需要的流动资金的总和。建筑工程 造价管理是一个极其重要的管理形式, 科学的工程造价管理 可以确保工程的建筑质量和工程进度, 有效控制建筑工程的 成本, 实现以最小的成本付出实现最大的收益。目前, 我国建 筑市场还处于价格竞争的阶段, 价格低在很大程度上可以确 保企业在竞争中处于优势地位。而工程造价管理则能够通过 加强企业内部管理的办法降低建设成本, 增强价格竞争力, 最大化的实现企业利润, 以利企业健康发展。

\section{2 我国当前建筑工程造价管理出现的问题}

2.1 造价管理信息滞后, 控制管理被动

虽然我国建筑行业发展很快, 但是由于起步低, 发展过 程中还是出现了各种问题, 其中, 造价管理信息传输滞后问 题就较为突出。信息滞后, 究其原因还是工程造价管理的基 础没有打劳, 能力发展不够造成的。而现代化的造价管理急 需建立起一套与之相适应的造价模式和信息收集方式。

随着信息技术的进步,一些给人们提供了极大便利的软 件得到快速应用, 为工程造价服务的系列软件投入使用就是 如此。这些软件用技术手段顺利实现了工程造价的精准、正 确, 圆满解决了工程造价中出现的计算问题。同时, 相关信息 平台的出现, 大大便利了信息的交流与沟通, 解决了信息滞 后的问题, 促成了我国工程造价管理信息收集工作的初步完 成。

目前, 新技术刚刚出现, 但是传统的管理模式仍有很大 的影响, 一些管理者思想还是比较僵化, 管理意识淡薄, 这使 得信息收集工作比较被动, 收集的信息很少, 远不能反映工 程的真实造价, 无法满足企业和市场的需要。目前, 建筑工程 的造价管理的重要意义还没有被我国大部分建筑企业所发
现和认识, 这就导致造价管理工作一直处于被动状态。造价 预算结果不正确, 不能反映真实的工程预算, 使得工程预算 工作包括其他各项预算管理和造价都与实际脱节, 落后于社 会需要, 造成成本控制工作无法落到实处。

2.2 成本管理问题严重, 工程造价不合理

目前, 我国大多数建筑企业管理意识淡漠, 成本控制工 作问题严重, 管理人员随意性严重, 经常随便更改工程设计, 不注重施工技术的更新升级等, 造成严重的人、财、物力的 浪费, 增加了成本的支出。同时, 目前比较常用的造价管理方 法不够科学, 进而导致企业在招标时胡乱更改价格, 压低价 格, 有的企业甚至玩起了价格战, 或者随意更改工程标准和 施工的设计方案, 牺牲工程质量, 用不当手段进行竞争。同时, 有的企业瞒报、谎报重要的指标数据, 乱报价乱收费, 增加了 工程的成本支出, 这些行为严重影响了造价管理的科学性。

\section{3 造价管理的技术薄弱}

从上面的叙述中可以看出, 我国的工程造价管理还是比 较落后的, 其原因之一就在于合格的工程师的缺之。目前, 我国的造价工程师总体水平不高, 专业化程度还比较低, 职 业技能还无法满足行业发展的要求, 还不能应付岗位职责的 需要。但由于我国社会发展较为迅速, 人们对造价工程师的 要求却越来越高, 因此, 应该首先加强工程师队伍的建设, 提 高造价工程师自身素质和专业技术能力, 提高其实际工作经 验和能力。以便其能够较好处理工程建筑中各部门的关系, 同时要高度重视工程建筑施工中现场勘查的重要作用, 以便 为工程师制定出科学、准确、合理的工程文件和为预算的编 制提供依据, 保证施工方案的科学性与合理性, 确保预算结 果准确无误。

\section{3 完善建筑工程造价的办法}

3.1 加强造价信息管理

近年来, 随着科技在人们工作和生活中的作用日益重要, 人们更加注意应用科技来改善自己的工作状态和环境, 降低 劳动强度。在这种背竟下, 作为新兴科技的代表, 信息技术得 到了广泛的应用, 人们开发出越来越多的应用软件, 让信息 技术更好地造福人类。在造价的信息管理方面, 人们就充分 发挥了信息技术的优越性,利用信息技术,收集造价管理的 
信息, 扩大信息库的容量, 为快速实现造价管理的信息化打 下坚实的基础。为此, 企业要建立专业的信息化的造价信息 收集部门, 专门收集管理各种造价信息, 同时鉴于信息技术 有更新快的特点, 要经常性的组织从业者进行信息化造价管 理的培训。要学会利用信息技术, 对收集到的造价管理信息 进行分析、归纳、整合, 进行专业比对与核实。经过信息化 的操作得出了结果还要学会将其运用到工作中, 将其更好的 运用到现实的建筑工程造价管理中, 以加强企业的管理工作, 实现工程造价管理的目的, 即让工程造价处在一个合理的水 平上,并保证工程质量。在信息化技术条件下,企业还应勇于 尝新管理模式, 不断吸收一切先进的管理方法为己所用, 把 建筑工程造价管理落到实处, 促进企业经济效益的提升。

\section{2 建立合理的管理体系}

想搞好建筑工程造价管理, 就要先建立起科学的、合理 的工程造价管理体系。如此, 就可以让施工设计、施工技术、 项目材料等环节的管理工作变得更为有序, 让组织工作更为 科学, 减少浪费, 节约资源。同时, 建立科学合理的管理体系 也有助于提高管理人员的包括业务能力在内的综合素质, 加 强其职业道德的培养, 熟练掌握相关机械的知识和使用方法, 最后达到提升造价管理水平的目的。

\section{3 编制合理的预算方案}

只有在保证建筑工程安全、质量和进度的前提下, 建筑 工程造价管理才能有效制定出工程预算。从技术方面来说, 严格、合理地分析施工预算方案的经济性和技术性, 合理准 确的设计出施工中所需要的财力、物力和人力, 是保证施工 方案有效的前提, 是最终确定预算方案的重要环节。此外, 在具体施工时, 要积极引进先进的施工工艺, 多采用先进的 技术手段, 提高工程的施工效率, 促进工程的造价管理。为此, 编制工程的预算方案要坚持与工程实际相结合, 要深入了解 施工方案的相关文件, 熟悉施工场地环境, 保证方案的科学 与合理、有效, 以编制出能够有效节约成本的预算方案。

\section{4 建筑工程项目造价管理的前景}

当前, 我国社会发展极为迅速, 社会面貌日新月异, 变化 极快, 城市化水平也在快速提高, 这意味着我国的建筑工程 将会迎来新的发展时期, 并会对经济发展发挥出越来越重要 的作用。在这技术和社会面貌快速发展变化的背景下, 我国 建筑工程项目造价管理将会有新的发展变化。

\section{1 完善建筑工程造价管理信息系统}

随着信息技术在建筑工程造价管理中的应用,有效降低
了管理者的工作强度和难度, 提高了工程造价的水平, 促进 了建筑造价造价行业的发展, 在可以预计的将来, 建筑工程 造价信息管理系统的发展将会更为清晰可见。

(1) 建立完善工程造价信息网。建立建筑工程信息网将 彻底改变以前的信息交流不畅的局面,加快企业间的信息交 流, 让传统的单一造价信息变为多向信息流动, 加强了造价 管理人员的沟通和交流, 有助于其分享经验和信息, 讨论解 决工作中发现的问题, 互相学习, 提高自身的业务水平和能 力, 提高建筑造价管理的水平。

(2) 完善数据库的建设。由于当前建筑工程存在着极为 复杂的情况, 规模性质各有不同, 需要收集的信息极为浩大, 同时也需要进行对比度分析，以提高信息资料的利用效率。 而随着造价管理工作的深入发展, 建立建筑工程造价管理数 据库成为一项重要的工程。该数据库能收集记录各种类型的 工程的详细信息, 包括工程的施工年限、施工捷段、造价书 等具体信息和造价管理的基本资料, 还可以同国家和相关政 府部门的网站建立连接, 为其提供检索服务, 便于相关人员 获取工程的造价信息。

\section{2 实行有梯度的人才管理}

人才是企业发展的核心要素, 也是工程造价管理的核 心。因此在未来工作中, 造价管理单位要有目的的加强人才 的培养, 要同高校建立起经常性的联系, 设立实习岗位, 积极 招收实行生, 为实习生的提供实践的机会, 提高其水平, 加强 人才队伍的梯队建设, 进而为开展造价管理提供源源不断的 人才供应。

\section{5 结束语}

总而言之, 因建筑工程具有投入的资金较多、工期周期 长等特点, 所以就要将造价控制工作细分到每一个环节, 只 有对每一个环节进行合理的成本控制, 才能减少建筑整体的 过度损耗情况, 进而提升企业的经济效益, 使其获得更有利 的市场竞争优势。

\section{[参考文献]}

[1]姚宁.建筑工程造价影响因素分析及降低工程造价 措施[J].江西建材,2018,(04):39.

[2]万明亮.建筑工程造价常见问题及对策分析[J].城市 建设理论研究(电子版),2018,(18):28.

[3]杨春.建筑工程管理中全过程造价控制的重要意义 [J].绿色环保建材,2018,(07):200+202. 